\title{
Critical appraisal of elvitegravir in the treatment of HIV-I/AIDS
}

This article was published in the following Dove Press journal:

HIVIAIDS - Research and Palliative Care

16 May 2014

Number of times this article has been viewed

\author{
Krishan K Pandey \\ Institute for Molecular Virology, \\ Saint Louis University Health \\ Sciences Center, St Louis, MO, USA
}

Correspondence: Krishan K Pandey Institute for Molecular Virology, Saint Louis University Health Sciences Center, I I00 S. Grand Blvd, Saint Louis, MO 63104, USA

Tel + I 3|4 9778787

Fax + I 3149778798

Email pandeykk@slu.edu

\begin{abstract}
Human immunodeficiency virus type 1 (HIV-1) integrase inhibitors belong to a novel class of antiretroviral drugs with high potency and better tolerability. Elvitegravir (EVG) is the second integrase inhibitor approved by the US Food and Drug Administration when administered in combination with a novel pharmacoenhancer, cobicistat (COBI), and two nucleoside/nucleotide reverse transcriptase inhibitors, emtricitabine (FTC) and tenofovir disoproxil fumarate (TDF). This combination of drugs (EVG/COBI/FTC/TDF) developed and marketed by Gilead Sciences Inc. (Foster City, CA, USA) as STRIBILD ${ }^{\circledR}$, is the first integrase inhibitorbased single-tablet regimen administered once-daily. In the USA, it has been approved for use in antiretroviral treatment-naïve HIV-1 patients with estimated creatinine clearance of $>70$ $\mathrm{mL} / \mathrm{min}$. The Department of Health and Human Services has approved EVG/COBI/FTC/TDF as one of preferred first-line regimens for HIV-1 treatment. In Europe, the European Medicines Agency has approved STRIBILD in treatment-naïve patients as well as in patients having no resistant mutation to any of the antiviral agents contained in STRIBILD. Its availability as a fixed-dose combination and once-daily dosage makes the adherence highly likely. However, it also discounts the possibility of dosage adjustment if needed.
\end{abstract}

Keywords: STRIBILD, INSTI, integrase, EVG/COBI/FTC/TDF

\section{Introduction}

It was nearly 30 years back when the first case of human immunodeficiency virus type 1 (HIV-1) infection in humans was reported and the causative virus was isolated. ${ }^{1,2}$ Since then, there has been remarkable progress in understanding the HIV-1 pathogenesis and development of AIDS (acquired immunodeficiency syndrome). These 30 years have resulted in the approval of an approximately equal number of drugs for HIV-1 treatment (Table 1). The introduction of highly active antiretroviral therapy in the mid-1990s led to a marked reduction in HIV-1 associated morbidity and mortality, accompanied by significant improvement in the quality of life of HIV-1-infected individuals. ${ }^{3}$ In the early stages of drug development for HIV-1, most of the drugs were targeted against HIV-1 reverse transcriptase and protease. However, life-long administration of drugs required to contain viral replication to a minimum level causes the emergence of drugresistant mutants and possibly the failure of an ongoing treatment regimen. The adverse events associated with these two classes of drugs occasionally results in unmanageable conditions, leading to discontinuation of treatment. Hence, the need for the development of new drugs with novel mechanisms of inhibition and better tolerability is an ongoing process. Early drug development efforts targeting the third HIV-1 enzyme, integrase (IN), were not successful, despite the fact that there is no cellular homologue 
Table I FDA-approved drugs for treatment in HIV-I-infected patients

\begin{tabular}{|c|c|c|c|c|c|}
\hline \multicolumn{2}{|l|}{ Reverse transcriptase } & \multirow[t]{2}{*}{ Protease } & \multirow[t]{2}{*}{ Integrase } & \multirow[t]{2}{*}{ Fusion } & \multirow[t]{2}{*}{ CCR5 } \\
\hline NRTIs & NNRTIs & & & & \\
\hline \multirow[t]{2}{*}{ Abacavir (ABC) Ziagen ${ }^{\mathrm{a}}$} & Delavirdine & Amprenavir (APV) & Dolutegravir & Enfuvirtide (T20) & Maraviroc (MVC) \\
\hline & (DLV) Rescriptor & Agenerase $^{\mathrm{a}}$ & (DTG) Tivicay ${ }^{\mathrm{e}}$ & FUZEON ${ }^{\otimes i}$ & SELZENTRY \\
\hline \multirow[t]{2}{*}{ Didanosine (ddl) Videx ${ }^{b}$} & Efavirenz (EFV) & Atazanavir (ATV) & Elvitegravir (EVG)- & & \\
\hline & Sustiva ${ }^{\mathrm{b}}$ & REYATAZ ${ }^{\circledR b}$ & as part of STRIBILD ${ }^{\circledR C}$ & & \\
\hline \multirow[t]{2}{*}{ Emtricitabine (FTC) Emtrivac } & Etravirine (ETR) & Darunavir (DRV) & Raltegravir (RAL) & & \\
\hline & INTELENCE ${ }^{\circledR f}$ & PREZISTA ${ }^{\circledast f}$ & ISENTRESS ${ }^{\oplus \mathrm{h}}$ & & \\
\hline \multirow[t]{2}{*}{ Lamivudine (3TC) Epivir ${ }^{\mathrm{a}}$} & Nevirapine & Fosamprenavir & & & \\
\hline & (NVP) Viramunes & $(\mathrm{FPV})$ Lexiva $^{\mathrm{e}}$ & & & \\
\hline \multirow[t]{2}{*}{ Stavudine (d4T) Zerit ${ }^{\mathrm{b}}$} & Rilpivirine & Indinavir (IDV) & & & \\
\hline & EDURANT ${ }^{\circledR f}$ & Crixivan $^{\text {h }}$ & & & \\
\hline \multirow[t]{2}{*}{ Tenofovir (TDF, TFV) Viread ${ }^{c}$} & & Nelfinavir (NFV) & & & \\
\hline & & Viracept $^{\mathrm{e}}$ & & & \\
\hline \multirow[t]{4}{*}{ Zidovudine (AZT, ZDV) Retrovir ${ }^{2}$} & & Ritonavir (RTV) & & & \\
\hline & & NORVIR ${ }^{\circledR \mathrm{d}}$ & & & \\
\hline & & Saquinavir (SQV) & & & \\
\hline & & Invirase $\mathrm{e}^{\mathrm{g}}$ & & & \\
\hline Combination drugs & & Tipranavir (TPV) & & & \\
\hline ATRIPLA ${ }^{\mathrm{b}, \mathrm{c}}$ (efavirenz/emtricitabine/ & & Aptivus ${ }^{8}$ & & & \\
\hline \multicolumn{6}{|l|}{ tenofovir) } \\
\hline \multicolumn{6}{|l|}{ COMBIVIR ${ }^{\circledR a}$ (lamivudine/zidovudine) } \\
\hline \multicolumn{6}{|l|}{ Complerac (emtricitabine/rilpivirine/tenofovir) } \\
\hline \multicolumn{6}{|l|}{ EPIZICOM ${ }^{\mathrm{a}}$ (abacavir/lamivudine) } \\
\hline \multicolumn{6}{|l|}{$K_{\text {KALETRA }}{ }^{\oplus \mathrm{d}}$ lopinavir/ritonavir (LPV/r) } \\
\hline \multirow{2}{*}{\multicolumn{6}{|c|}{$\begin{array}{l}\text { STRIBILD` (elvitegravir/cobicistat/emtricitabine/ } \\
\text { tenofovir) }\end{array}$}} \\
\hline & & & & & \\
\hline \multicolumn{6}{|l|}{ Trizivira (abacavir/lamivudine/zidovudine) $^{a}$} \\
\hline TRUVADAc (emtricitabine/tenofovir) & & & & & \\
\hline
\end{tabular}

Notes: Copyright $\odot 20$ I I. Adapted with permission from Pandey KK. Raltegravir in HIV-I infection: safety and efficacy in treatment-naive patients. Clin Med Rev Ther. 20I I;20 I 2(4): I 3-30. ${ }^{6}$

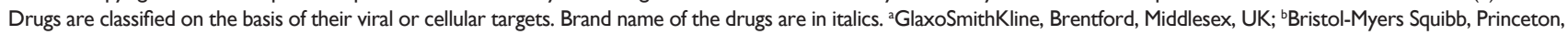
NJ, USA; 'Gilead Sciences Inc., Foster City, CA, USA; ' ${ }^{\mathrm{A}} \mathrm{bb}$ Vie Inc., North Chicago, IL, USA; 'ViiV Healthcare, Brentford, Middlesex, UK; flanssen Therapeutics, Titusville, NJ, USA; \&Boehringer Ingelheim Pharmaceuticals Inc., Ingelheim, Germany; 'Merck \& Co. Inc., Whitehouse Station, NJ, USA; and 'F. Hoffmann-La Roche Inc., Basel, Switzerland. Abbreviations: FDA, US Food and Drug Administration; HIV-I, human immunodeficiency virus type I; NNRTI, non-nucleoside reverse transcriptase inhibitors; NRTI, nucleoside (nucleotide) reverse transcriptase inhibitor; CCR5, C-C chemokine receptor type 5.

for IN in humans. One of the main reasons was the lack of a high-resolution structure of full-length HIV-1 IN alone or in complexed form with its cognate deoxyribonucleic acid (DNA) substrate. Even today, there is no crystal structure of full-length HIV-1 IN available in either form.

Raltegravir (MK-0518), developed by Merck and Co, Inc. (Whitehouse Station, NJ, USA), was the first HIV-1 IN inhibitor approved by the US Food and Drug Administration (FDA), in 2007. It is marketed as ISENTRESS ${ }^{\circledR}$ and has been a component of one of the preferred HIV-1 treatment regimens as per the Department of Health and Human Services (DHHS) guidelines for the last few years. ${ }^{4}$ Raltegravir in combination with other antiretroviral drugs is also an acceptable regimen when toxicity or other factors prevent the use of a DHHS preferred regimen. Raltegravir has excellent tolerability, with potent antiviral efficacy. Raltegravir has been extensively used in treatment-naïve as well as in treatment-experienced patients as salvage therapy. ${ }^{5-7}$ Raltegravir is administered as a $400 \mathrm{mg}$ tablet twice-a-day (bid) in combination with tenofovir and emtricitabine (FTC). The limitations of raltegravir are a required twice-a-day dosing and a low genetic barrier to emergence of resistant mutations.

Elvitegravir (EVG) was the first HIV-1 IN inhibitor to be approved for HIV-1 treatment by the FDA, in 2012, as a combination drug (brand name STRIBILD ${ }^{\circledR}$; Gilead Sciences Inc., Foster City, CA, USA). STRIBILD is prescribed as a oncedaily single-tablet regimen, which contains $150 \mathrm{mg}$ of EVG, $150 \mathrm{mg}$ cobicistat (COBI), $200 \mathrm{mg}$ FTC, and $300 \mathrm{mg}$ tenofovir disoproxil fumarate (TDF). ${ }^{8} \mathrm{COBI}$ acts as a pharmacoenhancer to boost the effective concentration of EVG. FTC and TDF are the nucleoside and nucleotide inhibitors of HIV-1 reverse transcriptase and have been used as first-line HIV-1 therapy for several years. The once-daily single-tablet regimen significantly improves the adherence and decreases the emergence of resistant viral populations. ${ }^{9}$ This review summarizes the development of EVG from an investigational drug to an FDAapproved drug for HIV-1 treatment. 


\section{Mechanism of action}

During the HIV-1 lifecycle, once the virus enters the cell, its ribonucleic acid (RNA) genome is reverse transcribed to a double-stranded blunt-ended DNA by HIV-1 reverse transcriptase. The resulting viral DNA is transported via the pre-integration complex into the nucleus and is incorporated into the cellular genome by IN. It results in permanent infection of the cell and establishment of latent viral reservoirs. Hence, IN is an essential protein for viral replication. IN is formed by the proteolytic processing of the viral GagPro-Pol precursor. HIV-1 IN contains 288 amino acids and consists of three structural domains connected by flexible linkers. ${ }^{10}$ The N-terminal domain ( 1-47 amino acids) contains a zinc binding site (HHCC motif). The catalytic core domain ( $~ 59-202$ amino acids) contains the active site formed by a catalytic triad of three acidic residues called the DDE motif (D64, D116, and E152). The IN inhibitors chelates the two metal ions $\left(\mathrm{Mg}^{2+}\right)$ in the active site, which are essential for catalytic reactions performed by IN. The C-terminal domain ( 223-288 amino acids), contains an SH3 (Src homology 3 domain)-like fold that binds both the viral DNA and host DNA. ${ }^{11,12}$ The monomeric form of HIV-1 IN efficiently multimerizes onto the DNA ends to perform the concerted integration of viral DNA ends into target DNA in vitro. ${ }^{13}$ Concerted integration is believed to be carried out by a tetrameric IN complex bound to two viral DNA ends. ${ }^{14-16}$

HIV-1 IN removes the terminal dinucleotide (GT) adjacent to invariant CA nucleotides from each $3^{\prime}$-end of bluntended viral DNA, referred to as the cleaved strand. This step is also referred as $3^{\prime}$-processing. Upon nuclear transport of 3'-OH recessed DNA, IN makes a nick into opposite strands of cellular DNA separated by five base pairs and mediates the joining of viral DNA ends into the host DNA. This second reaction is termed "strand transfer." This latter step is crucial, as it incorporates a copy of viral genome into the host DNA, thereby making the infection permanent. Transcription and translation of viral genome by host machinery results in the production of the viral RNA genome and polypeptides, which ultimately results in the maturation and production of new viral particles. Most of the IN inhibitors, including raltegravir, EVG, and dolutegravir (three FDA approved drugs), inhibit the strand transfer reaction by preventing the joining of viral DNA ends to the host DNA. Due to their mode of action of inhibition of strand transfer, this class of inhibitors is termed "IN strand transfer inhibitors" (INSTIs). INSTIs, including EVG, bind to and inactivate the IN-viral-DNA complex, thereby preventing the binding of host DNA and thus inhibiting the strand transfer. ${ }^{17-19}$ INSTIs at the effective concentrations (half maximal inhibitory concentration $\left[\mathrm{IC}_{50}\right]$ ) have a minimal effect on $3^{\prime}-\mathrm{OH}$ processing activity of IN. Detailed understanding of INSTI-mediated inhibition came from prototype foamy virus (PFV) intasome crystal structures with INSTIs. ${ }^{20} \mathrm{PFV}$ IN is also inhibited efficiently by HIV-1 INSTIs. EVG binds to PFV IN-DNA complex as an interfacial inhibitor in the IN catalytic site. EVG interacts with PFV IN residues in the active site and through van der Waals interactions with CA dinucleotides on the cleaved strand and the fourth nucleotide " $G$ " from the 5 '-end of the non-cleaved strand. These interactions result in displacement of the terminal 3'-adenosine of the cleaved strand from the active site of IN. ${ }^{20}$ Molecular modeling studies based on INSTI interactions with PFV intasome have suggested a similar mode of inhibition for HIV-1 IN. ${ }^{21}$

\section{Development of EVG}

EVG was developed from quinolone antibiotics as the chemical backbone. ${ }^{22}$ It was originally discovered at Central Pharmaceutical Research Institute of Japan Tobacco, Inc. and known as JTK-303. Later, JTK-303 was licensed to Gilead Sciences Inc. (named as GS-9137) for clinical development and commercialization of the drug world-wide excluding Japan. EVG maintains the structure similar to the diketo acid moiety (Figure 1) believed to be essential for inhibition of HIV-1 IN through chelation of metal ions in the active site. The diketo acid moiety is a key part of most clinical IN inhibitors that have been developed. The beta ketone and carboxylic acid (mono-keto acid) groups in EVG bind to the

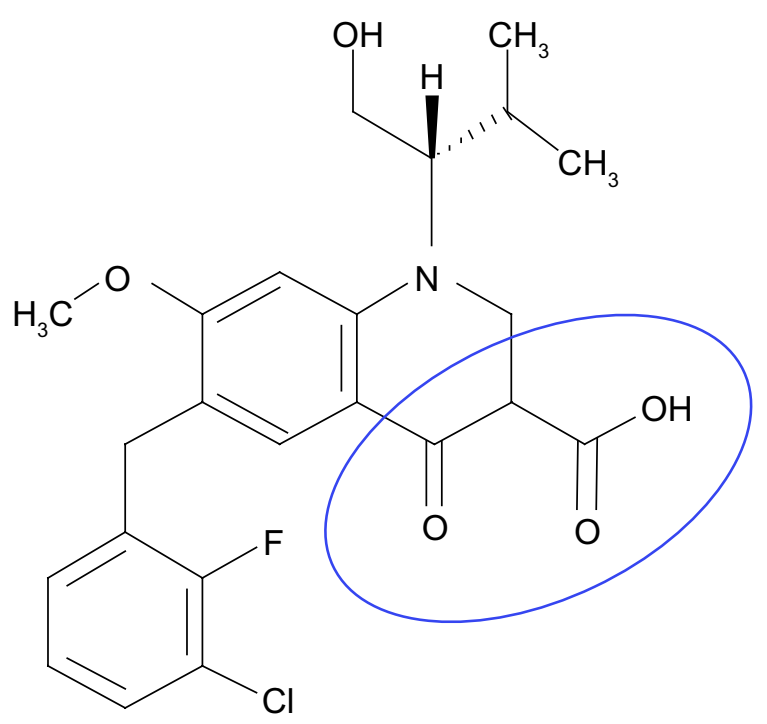

Figure I Chemical structure of elvitegravir (JTK-303, GS-9137. Chemical name 6-(3-chloro-2-fluorobenzyl)-I-[(2S)-I-hydroxy-3-methylbutan-2-yl]-7-methoxy4-oxo-I, 4-dihydroquinoline-3-carboxylic acid). The active pharmacophore which chelates the metal ion in integrase active site is circled in blue. 
divalent metal ions, and the aromatic hydrophobic groups (halobenzoyl) bind to IN and viral DNA. EVG has an $\mathrm{IC}_{50}$ of $7.2 \mathrm{nM}$ to inhibit strand transfer based on immobilized assays. The half maximal effective concentration $\left(\mathrm{EC}_{50}\right)$ was shown to be $0.9 \mathrm{nM}$ in HIV-1 infection assays. EVG also inhibited the concerted integration reaction of HIV-1 IN, with an $\mathrm{IC}_{50}$ of $8.5 \mathrm{nM}$ in vitro. ${ }^{17}$

\section{Metabolism and pharmacokinetics}

EVG is primarily metabolized via cytochrome $\mathrm{p} 450$ isoenzyme 3A4 (CYP3A4) pathway in the liver and intestines. ${ }^{23} \mathrm{~A}$ small part of EVG is also metabolized via glucuronidation mediated by uridine diphosphate glucuronosyltransferase (UGT1A1). ${ }^{23}$ Metabolites M1 and M4 formed by these pathways have significantly lower antiviral potency than EVG. M1 is produced by CYP3A4, while M4 is produced in the UGT1A1 pathway. ${ }^{23}$ In contrast, raltegravir and dolutegravir are predominantly metabolized via glucuronidation by UGT1A1. ${ }^{24,25}$ EVG is predominantly (94\%) excreted though the feces; most of the remaining is excreted through the urine. ${ }^{23}$

The first study to evaluate the safety, tolerability, and pharmacokinetics of EVG was done in Japanese healthy male individuals $(n=32)$. The subjects in each group (six active, two placebo) were given a single dose of increasing amounts of EVG $(100,200,400$, and $800 \mathrm{mg})$ in a fasted state. ${ }^{26}$ The group with the $400 \mathrm{mg}$ dose also received a similar dose (400 mg) of EVG under fed conditions after a washout period of more than 10 days. The pharmacokinetics was carried out over 24 hours post-dose. The peak plasma concentration $\left(\mathrm{C}_{\max }\right)$, or maximum concentration after a dose is given, and the area under the concentration curve (AUC) increased with an increasing dose of EVG; however, the rate of increase was not proportional to the dose. $\mathrm{C}_{\max }$ in the plasma was achieved at 0.5-4.0 hours with the increase in dose concentration. Plasma concentration of EVG 12-24 hours post-dose was higher than protein-binding-adjusted $\mathrm{EC}_{50}(16 \mathrm{nM})$ in human peripheral blood mononucleated cells. The results suggested that EVG was orally bioavailable. The group which received EVG under fed conditions, had threefold higher $\mathrm{C}_{\max }$ and AUC compared with the groups in the fasting state. This suggested that EVG should probably be given with food. EVG at all dosages was tolerable, and no serious adverse events were reported. ${ }^{26}$

Since EVG is metabolized via the CYP450 pathway, it was natural to find out whether its bioavailability was affected by inhibitors targeting the CYP450 pathway. Coadministration of EVG with ritonavir resulted in significant increase in bioavailability and half-life of EVG. ${ }^{27}$ Ritonavir is an HIV-1 protease inhibitor and has been used extensively for more than 10 years for treatment of HIV-1 infected individuals. Apart from its anti-HIV-1 activity, ritonavir also inhibits human CYP3A. Due to this property, ritonavir has been used to improve the pharmacokinetics of other HIV-1 protease inhibitors, which are also predominantly metabolized by CYP3A. A systematic dose-response of ritonavir on CYP3A activity and EVG bioavailability determined $100 \mathrm{mg}$ ritonavir once-daily as the optimal dose. ${ }^{28}$ Healthy individuals ( $n=12$, each arm) were given multiple does of ritonavir (20,50,100, and $200 \mathrm{mg}$ once-daily) in combination with EVG (125 mg) once-daily. Maximum reduction of hepatic CYP3A was observed with 100 and $200 \mathrm{mg}$ ritonavir. $\mathrm{C}_{\max }$ and trough plasma concentration $\left(\mathrm{C}_{\text {trough }}\right)$ for EVG increased with increasing dose of ritonavir from 20 to $100 \mathrm{mg}$, but there was no significant difference between 100 and $200 \mathrm{mg}$ ritonavir. Hence, a $100 \mathrm{mg}$ dose of ritonavir was selected for further efficacy studies. Coadministration of EVG with ritonavir did not alter the pharmacokinetics of commonly used nucleoside/nucleotide reverse transcriptase inhibitors including FTC and tenofovir. ${ }^{29}$ The probable reason for non-interaction is that FTC and tenofovir follow different metabolic and excretory pathways. FTC and tenofovir at the concentrations used (200 and $300 \mathrm{mg}$, respectively) do not inhibit the metabolism by CYP450. ${ }^{30}$ The pharmacokinetics of ritonavir-boosted EVG $(85 \mathrm{mg})$ in adolescent HIV-1 infected patients was similar to the adult populations, with mean $\mathrm{C}_{\text {trough }} \sim 7-13$-fold above the $95 \%$ inhibitory concentration $\left(\mathrm{IC}_{95}\right)$.

Despite the promising effect of ritonavir on enhancing the bioavailability of EVG and other HIV-1 drugs, ritonavir has several limitations when used as a pharmacoenhancer (eg, increased serum lipid levels and gastrointestinal disorders). ${ }^{31,32}$ Emergence of resistance mutations in protease also occurs when ritonavir is used at a suboptimal dose as a booster agent. Due to its lower specificity, ritonavir also inhibits unintended multiple pathways (CYP, UGT) and transporters. ${ }^{32}$

Efforts to develop an alternative pharmacoenhancer to ritonavir possessing the intended properties resulted in the discovery of COBI (GS-9137). COBI was developed as a novel inhibitor of CYP3A4. It did not possess anti-HIV-1 activity and, similar to ritonavir, was an effective enhancer of EVG and other antiretroviral drugs. ${ }^{28,33}$ COBI-boosted EVG should be administered with food to gain higher effective concentration. ${ }^{34}$ The AUC to infinity $\left(\mathrm{AUC}_{\infty}\right.$ ) and $\mathrm{C}_{\max }$ for EVG increased $34 \%$ and $22 \%$, respectively, with a low calorie diet (373 kcal, 20\% fat). The increase in $\mathrm{AUC}_{\infty}$ and 
$\mathrm{C}_{\max }$ was more significant (87\% and $56 \%$, respectively) when EVG/COBI/FTC/TDF was taken with high calorie/ high fat food ( $800 \mathrm{kcal}, 50 \%$ fat) compared with the fasted state. COBI possesses higher specificity towards inhibiting CYP3A $4{ }^{35}$ and is also being used as a boosting agent for protease inhibitors atazanavir and darunavir. ${ }^{36}$ In a Phase I study with EVG/COBI/FTC/TDF, the fixed-dose regimen containing $150 \mathrm{mg}$ COBI, the bioavailability of EVG was enhanced to a similar level as observed when boosted with $100 \mathrm{mg}$ ritonavir, providing $\mathrm{C}_{\text {trough }}$ values $\sim 11$-fold higher than the protein-binding-adjusted $\mathrm{IC}_{95}{ }^{37}$ This 10 -day open-label study $(\mathrm{n}=44)$ directly compared the pharmacokinetic and boosting properties of $\mathrm{COBI}$ against ritonavir on $\mathrm{EVG}$ when given in combination with FTC and tenofovir. The half-lives of tenofovir and FTC were unchanged when administered as part of fixed-dose EVG/COBI/FTC/TDF versus concomitant administration. $^{37}$

The effective plasma concentration of EVG is lower when $\mathrm{EVG} / \mathrm{COBI} / \mathrm{FTC} / \mathrm{TDF}$ is administered simultaneously with antacids. The binding of di- and trivalent metal ions present in antacids to EVG likely decreases its effective concentration. However, a 2-hour separation in antacid administration to EVG/COBI/FTC/TDF does not affect EVG absorption. ${ }^{38}$ Similar staggering of antacids is recommended with other IN inhibitors raltegravir and dolutegravir. ${ }^{39,40}$ Detailed descriptions of pharmacokinetics of EVG with ritonavir and COBI and its interaction with other HIV-1 drugs have been previously published. ${ }^{23,41}$

\section{Clinical trials to determine efficacy and safety}

The first monotherapy trial in HIV-1-infected patients $(\mathrm{n}=40)$ with EVG exhibited potent antiviral activity with acceptable safety and tolerability. ${ }^{27}$ Increasing dose of EVG (200, 400, or $800 \mathrm{mg}$ bid) or $800 \mathrm{mg}$ once-a-day (qd) was administered to treatment naïve and treatment-experienced individuals not receiving antiretroviral therapy in the past 90 days. In another group, $50 \mathrm{mg}$ EVG was boosted with $100 \mathrm{mg}$ ritonavir (qd) in the morning with food ( $\mathrm{n}=6$ for each arm, $\mathrm{n}=10$ for placebo). The patients had HIV-1 RNA levels between 10,000 and 300,000 copies $/ \mathrm{mL}$ and had more than $200 \mathrm{CD}^{+}$cells/ $\mathrm{mL}$. At higher doses of EVG (400 and $800 \mathrm{mg}$ bid), the mean $\mathrm{C}_{\text {trough }}$ was higher than the protein-binding-adjusted $\mathrm{IC}_{95}$. For EVG, the time to reach maximum plasma concentration $\left(\mathrm{T}_{\max }\right)$ was $\sim 3-4$ hours and half-life of $\sim 3$ hours when dosed alone. Ritonavir coadministration (100 mg) significantly boosted the EVG (50 mg qd) elimination half-life to $\sim 9$ hours and maintained the $\mathrm{C}_{\text {trough }}$ above the $\mathrm{IC}_{95}$ for more than 48 hours after the dosing. This proved that boosting of EVG with ritonavir (50 mg/100 mg qd) maintains the EVG concentration in an active therapeutic range, which was not possible even with twice-a-day dosing schedule. Patients in three groups ( 400 and $800 \mathrm{mg}$ bid and $50 \mathrm{mg}$ boosted with $100 \mathrm{mg}$ ritonavir qd) responded well to the treatment and exhibited mean reduction of HIV-1 RNA of $\geq 1.91 \log _{10}$ copies $/ \mathrm{mL} .{ }^{27}$ Encouraging results from this study paved the way for further refinements in the EVG-based clinical trials.

The efficacy and safety of once-daily single-pill EVG/ COBI/FTC/TDF ( $\mathrm{n}=48$ ) against a single-pill EFV/FTC/TDF $(\mathrm{n}=23)$ was determined in a Phase 2 study (NCT00869557). ${ }^{42}$ Patients receiving EVG/COBI/FTC/TDF experienced a faster decline in viral RNA load and greater proportion of suppressed viral RNA to less than 50 copies/mL than EFV/FTC/ TDF (90\% versus $83 \%$ ) at 24 week and 48 weeks. The EVG $\mathrm{C}_{\text {trough }}$ in the EVG/COBI/FTC/TDF group was consistently higher (approximately tenfold) than the protein-bindingadjusted $\mathrm{IC}_{95}{ }^{42}$ Frequency of adverse events was comparable in the two study groups. None of the patients in the EVG arm discontinued treatment due to adverse events, while only one patient discontinued in the EFV arm due to side effects.

A Phase 3 study (NCT01095976, Gilead Study 102) conducted in North America determined the effectiveness of single-tablet regimens containing EVG/COBI/FTC/ TDF (150/150/200/300 mg, n=348) against EFV/FTC/TDF (600/200/300 mg, $n=352)$, the standard of care at the time..$^{43,44}$ The abovementioned treatments were given to 700 treatmentnaïve HIV-1-infected patients with HIV-1 RNA levels of more than 5,000 copies $/ \mathrm{mL}$. The patients had $\geq 70 \mathrm{~mL} / \mathrm{min}$ glomerular filtration rates. Results compiled at 48 weeks suggested that $\mathrm{EVG} / \mathrm{COBI} / \mathrm{FTC} / \mathrm{TDF}$ was non-inferior to EFV/FTC/TDF. The percentage of patients achieving less than 50 copies/mL RNA was higher with EVG/COBI/FTC/ TDF (87.6\%) than EFV/FTC/TDF (84.1\%). Non-inferiority of EVG/COBI/FTC/TDF versus EFV/FTC/TDF was maintained through a 96 -week time point ( $84 \%$ versus $82 \%$ ). Median adherence to the study drug was similar in both study groups ( $\sim 98 \%)$. Frequency of adverse events and discontinuation were comparable in the two arms of the study. Nausea was more prevalent in the EVG/COBI/FTC/TDF group, while insomnia, rash, and neuropsychiatric events were less frequent.

Adverse renal events have been a major cause of concern in EVG/COBI/FTC/TDF therapy. The number of patients who discontinued treatment due to adverse renal events in Study 102 was $\sim 2 \%{ }^{44}$ Five patients had discontinued treatment by 48 weeks due to adverse renal abnormalities 
(two patients each had increased creatinine concentration or renal failure, and one had Fanconi syndrome). Four of these patients had renal impairment issues before enrolling in the study. The rate of renal discontinuation was similar to other regimens which contained tenofovir with ritonavir boosted protease inhibitors. ${ }^{45}$ Serum creatinine concentration increased by week 48 in the EVG/COBI/FTC/TDF group (median $13 \mu \mathrm{mol} / \mathrm{L}$, interquartile range 5-20 $\mu \mathrm{mol} / \mathrm{L}$ ) compared with $(1 \mu \mathrm{mol} / \mathrm{L},-6$ to $8 \mu \mathrm{mol} / \mathrm{L})$ in the EFV/ FTC/TDF group. ${ }^{43}$ In most of the patients, serum creatinine level rose in the first 2 weeks and remained stable after that. The increase in creatinine could be associated with nonpathogenic decrease in effective glomerular filtration rate and inhibition of proximal tubular secretion by COBI. COBI inhibits the tubular secretion of creatinine by inhibition of renal secretory transporters, resulting in an increase of serum creatinine concentration, without reducing the actual glomerular filtration rate. ${ }^{46}$ Alternatively, this nephropathy might be genuinely caused by TDF, one of the components of EVG/COBI/FTC/TDF. ${ }^{47,48}$ Through 144 week of Study 102 , the changes in serum creatinine observed in the EVG/ COBI/FTC/TDF arm remained similar to those observed at 48 weeks. ${ }^{43,49}$ Between 48 and 96 weeks, only two patients discontinued treatment due to renal events, and none had proximal tubulopathy. ${ }^{44}$ The results reported for week 144 did not find any new renal adverse effect-related discontinuation. ${ }^{49}$ Close monitoring of creatinine clearance is recommended to distinguish between the non-pathogenic reduction of clearance due to COBI and pathologic nephrotoxicity caused by tenofovir.

Consistent with a raltegravir-based treatment regimen, ${ }^{50,51}$ the rate of decrease in viral load is faster with EVG/COBI/ FTC/TDF compared with EFV/FTC/TDF. Faster decline in viral load seems to be a hallmark of INSTIs. Frequency of development of resistance to EVG/COBI/FTC/TDF was similar to the EFV/FTC/TDF group at the end of 96 weeks. ${ }^{44}$ In the EVG/COBI/FTC/TDF group, ten patients (3.48\% of total) had emergent resistance mutations. E92Q was the most frequent mutation in IN (nine out of ten patients). All ten patients had nucleoside/nucleotide reverse transcriptase inhibitorresistant mutations. Viral load suppression $(<50$ copies $/ \mathrm{mL})$ was maintained until week 144 in both groups, with high rates (80.2\% versus $75.3 \%$ ). These results confirmed long-term efficacy and safety of EVG/COBI/FTC/TDF. ${ }^{49}$

In an independent Phase 3 study (NCT01106586, Gilead Study 103) done in parallel, non-inferiority of EVG/COBI/ FTC/TDF (150/150/200/300 mg) (n=353) was determined against ritonavir boosted atazanavir (ATV/RTV, 300/100 mg) with FTC/TDF $(200 / 300 \mathrm{mg})(\mathrm{n}=355)$ in treatment-naïve HIV-1-infected patients. ${ }^{52-54}$ Both study drugs were administered once-daily with food. EVG/COBI/FTC/TDF was found to be non-inferior to ATV/RTV + FTC/TDF. The percentage of patients that had HIV-1 RNA levels below 50 copies/mL was similar in both study groups at 48 and 96 weeks. This is an ongoing (total 192 weeks) international study conducted in North America, Australia, Europe, and Thailand. At 96 weeks, the treatment outcome was independent of sex, age, or race. Both treatment regimens were well tolerated, and adverse event-related discontinuation of treatment was similar.

In Gilead study 103, the median increase from baseline in serum creatinine in EVG/COBI/FTC/TDF was higher versus ATV/RTV+FTC/TDF $(12 \mu \mathrm{mol} / \mathrm{L}$ versus $8 \mu \mathrm{mol} / \mathrm{L})$ at 48 weeks. ${ }^{54}$ The initial increase in creatinine in serum is consistent with known effects of COBI; however, the increase in creatinine was stabilized in later weeks. ${ }^{52}$ Development of resistance to any component of the regimen in both study groups was low. No resistance mutations emerged in ATV/ RTV + FTC/TDF. A total of six patients (1.7\%) failed the treatment and developed resistance mutations in the EVG/ COBI/FTC/TDF arm, predominantly M184V; however, no IN mutations were observed by 96 weeks in patients who failed the treatment. ${ }^{52}$

A high rate of virologic success ( $<50$ copies/mL HIV-1 RNA) was maintained in both treatment groups at 144 weeks; $77.6 \%$ in the EVG/COBI/FTC/TDF group and $74.6 \%$ in the $\mathrm{ATV} / \mathrm{RTV}+\mathrm{FTC} / \mathrm{TDF}$ group. The mean $\mathrm{CD}^{+}{ }^{+}$cell increase from baseline was similar for both groups. ${ }^{53}$ Over the period of 144 weeks, eight patients (2.3\%) in the EVG/COBI/FTC/ TDF group developed resistance mutations comprising T66I, E92Q, Q148R, N155H, and T97A in IN, and M184V/I and $\mathrm{K} 65 \mathrm{R}$ in reverse transcriptase. In the ATV/RTV + FTC/TDF group, only two patients developed mutations (M184V/I) in reverse transcriptase. ${ }^{53}$ The pattern of treatment discontinuation due to related adverse events through week 144 was similar to week 96. EVG/COBI/FTC/TDF was tolerated better than ATV/RTV + FTC/TDF. Through week 144, 21 subjects $(5.9 \%)$ discontinued due to adverse effects in the EVG/COBI/FTC/TDF group compared with 30 subjects $(8.5 \%)$ in the ATV/RTV + FTC/TDF group. Adverse renal events were less frequent after 96 weeks in the EVG/COBI/ FTC/TDF group. Similarly, the changes in creatinine level from baseline were observed in the first 2 weeks only and stabilized thereafter through week 144. Fractures occurred in ten $(2.8 \%)$ patients in the EVG/COBI/FTC/TDF group compared with $19(5.4 \%)$ in the ATV/RTV + FTC/TDF 
group. Overall, EVG/COBI/FTC/TDF as a single once-daily pill was non-inferior to ATV/RTV + FTC/TDF and had a better safety profile..$^{53}$

A recent report from the FDA differed from results presented in Phase III studies on creatinine level increase in individuals on $\mathrm{EVG} / \mathrm{COBI} / \mathrm{FTC} / \mathrm{TDF}$ versus the comparator arm EFV/FTC/TDF and ATV/RTV + FTC/TDF. ${ }^{55}$ The FDA report recommendations included determining estimated creatinine clearance, urine glucose, and urine protein in patients before starting the EVG/COBI/FTC/TDF therapy and closely monitoring it during the treatment. The recommendations included not starting the treatment in patients with estimated creatinine clearance below $70 \mathrm{~mL} / \mathrm{min}$. Both the FDA and the Gilead study recommend close monitoring of the patients on EVG/COBI/FTC/TDF therapy who experience an increase in serum creatinine of more than $0.4 \mathrm{mg} / \mathrm{dL}$ from baseline.

\section{Efficacy of EVG compared with raltegravir}

Direct comparison of EVG, boosted with ritonavir (qd) against raltegravir (400 mg bid) showed similar efficacy and safety in patients in whom previous antiretroviral treatment had failed. This non-inferiority Phase III study (NCT0078162, Gilead Study 145) was done in treatment experienced patients $(n=724)$ who had plasma RNA levels of $>1,000$ copies $/ \mathrm{mL}$. Both study groups, raltegravir $(\mathrm{n}=363)$ and EVG with ritonavir $(\mathrm{n}=361)$, were also administered a background regimen through 96 weeks. Data reported for 48 weeks suggested non-inferiority of the EVG-based treatment regimen to raltegravir. ${ }^{56}$ Both the regimens were well tolerated and showed a similar rate of adverse events through 96 weeks. ${ }^{57}$ The rate of discontinuation was similar in both treatment groups. However, single-pill dosage for EVG is more advisable to enhance the adherence to the treatment compared with the twice-a-day dosing required for raltegravir. Efficacy, safety, and tolerability of EVG/ COBI/FTC/TDF was compared in patients who had suppressed viremia on raltegravir (plus FTC/TDF)-based bid therapy. The subjects ( $\mathrm{n}=48)$ in this Phase $3 \mathrm{~b}$ switching study (NCT01533259, Gilead Study 123) were on raltegravir (bid) therapy (plus FTC/TDF) and maintained viral load below 50 copies $/ \mathrm{mL}$ for at least 6 months. Patients were switched to a once-daily single-tablet regimen of EVG/COBI/FTC/ TDF and followed for 48 weeks. All patients maintained a viral load below 50 copies $/ \mathrm{mL}$ and high $\mathrm{CD}^{+}$cells at week 24 post-switch. There were no serious adverse events and no drug-related discontinuation. Effective glomerular filtration rate was unaffected over the course of 24 weeks. Hence, switching from twice-a-day treatment to once-daily single-tablet regimen will lead to an effective and simplified treatment regimen with higher adherence. ${ }^{58}$

\section{Resistance mutations}

One of the hallmark features of antiviral drugs for HIV-1 has been their eventual loss of efficacy due to development of resistance mutations in the viral genome. EVG is no exception to this phenomenon; rather it has a low genetic barrier similar to raltegravir. Even a single non-polymorphic mutation in IN diminishes the sensitivity to EVG. In vitro (cell culture) selection with EVG leads to the identification of T66I and E92Q as primary substitutions. These substitutions are located near the active site of IN. ${ }^{59}$ T66I and E92Q mutations reduce EVG susceptibility nearly 10and 30-fold, respectively. Other predominant IN mutations which impart reduced susceptibility to EVG are H51Y, T66K, T97A, F121Y, S147G, Q148H/R/K, S153Y, N155H, and R263K. ${ }^{59-61} \mathrm{R} 263 \mathrm{~K}$ has also been reported to emerge with dolutegraviri ${ }^{62,63}$ and in patients receiving raltegravir. ${ }^{64}$ These mutations diminish viral replication fitness and catalytic activities of recombinant IN. ${ }^{17,59,60,65-68}$ Clinical trials with EVG in HIV-1-infected individuals have corroborated the in vitro findings. In patients on EVG/COBI/FTC/TDF (Study 103), T66I, E92Q, N155H, and Q148R were the predominant resistance mutations through 96 weeks. ${ }^{52}$ Similar mutations were observed in a parallel investigation (Study 102), where EVG/COBI/FTC/TDF was compared with EFV/FTC/TDF. ${ }^{44}$ Unfortunately, most of the above IN mutations also provide cross-resistance to raltegravir; hence raltegravir-based therapy cannot be used in patients failing in EVG/COBI/FTC/TDF regimens and vice versa. However, these patients are still susceptible to a second-generation INSTI, dolutegravir. Dolutegravir is administered as a oncedaily dose without the need of a booster agent, although it is not yet available as a single-pill regimen.

\section{Place in therapy}

EVG is part of the combination of four drugs EVG/COBI/ FTC/TDF marketed as STRIBILD, which was approved as first-line treatment for treatment-naïve HIV-1-infected adults. It is the first IN inhibitor-based single-tablet regimen and is the major boasting property of this combination. STRIBILD is currently not approved for use in treatment-experienced patients in the USA. In Europe, STRIBILD is approved for treatment-naïve patients as well as patients who are not resistant to any of the antiviral components contained in 
STRIBILD. EVG is not available alone or in combination with other HIV-1 drugs. EVG/COBI/FTC/TDF is one of the "preferred regimens" designated by the DHHS for use in initial treatment of HIV-1 for patients with creatinine clearance rate of $>70 \mathrm{~mL} / \mathrm{min}$. EVG-based treatment has fewer central nervous system adverse effects and better lipid profile compared with other established treatments. In clinical studies, it is equally effective compared with raltegravir in treatment-experienced patients as well as in patients who switch from raltegravir-based treatment. EVG/COBI/FTC/ TDF is non-inferior to other treatment regimens considered to be the gold standard for HIV-1 treatment like EFV/FTC/ TDF (ATRIPLA ${ }^{\circledR}$; Bristol-Myers Squibb, Princeton, NJ and Gilead Sciences Inc., Foster City, CA, USA), another oncedaily single-tablet regimen. ${ }^{43}$ Once-daily dosing of EVG/ COBI/FTC/TDF may not be desirable in certain patients where dosing of individual components needs to be adjusted. EVG/COBI/FTC/TDF should not be initiated in patients with creatinine clearance $<70 \mathrm{~mL} / \mathrm{min}$ and should be discontinued if creatinine clearance becomes less than $50 \mathrm{~mL} / \mathrm{min}$.

Mild to moderate hepatic impairment in patients does not warrant avoidance of EVG/COBI/FTC/TDF therapy. However, due to lack of any clinical studies, EVG/COBI/ FTC/TDF is not recommended in patients with severe hepatic impairment. HIV-1 patients co-infected with mycobacterium tuberculosis, who are on rifampicin or rifabutin treatment, should not opt for EVG/COBI/FTC/TDF therapy. Rifampicin and rifabutin are potent inducers of CYP450, resulting in faster metabolism of EVG and significant reduction in EVG and COBI plasma concentrations.

\section{Conclusion}

With the availability of several classes of drugs, HIV-1 infection has become a manageable disease for a majority of populations with the access to treatment. Over the last few years, emphasis has been on developing single-tablet formulations to reduce the pill burden and improve adherence. Higher adherence to treatment has been associated with greater success of treatment and lower emergence of resistant mutations. A once-daily single-tablet formulation of EVG enables adherence to the treatment more likely with no loss of effectiveness compared with other standard treatments. It has proven to be non-inferior to other existing regimens in switching studies, suggesting it to be an alternative treatment option for patients. However, proper monitoring of serum creatinine level and renal functioning is highly recommended. Efforts are ongoing to target the other functionalities of IN. Multimerization of IN onto viral DNA ends to produce a tetrameric complex has been a novel drug target. A number of inhibitors referred to as allosteric IN inhibitors targeting the multimerization process have been identified and are in early clinical stages. ${ }^{69,70}$ Development of novel IN inhibitors in combination with existing treatment regimens should be helpful to patients in controlling HIV-1 replication and maintaining quality of life.

\section{Acknowledgments}

The author is supported by the National Institutes of Health Research Grant AI100682. The author would like to thank Dr Duane Grandgenett for the critical reading of the manuscript.

\section{Disclosure}

The author has no conflict of interest.

\section{References}

1. Barre-Sinoussi F, Chermann JC, Rey F, et al. Isolation of a T-lymphotropic retrovirus from a patient at risk for acquired immune deficiency syndrome (AIDS). Science. 1983;220(4599):868-871.

2. Gallo RC, Sarin PS, Gelmann EP, et al. Isolation of human T-cell leukemia virus in acquired immune deficiency syndrome (AIDS). Science. 1983;220(4599):865-867.

3. Perelson AS, Essunger P, Cao Y, et al. Decay characteristics of HIV-1-infected compartments during combination therapy. Nature. 1997;387(6629):188-191

4. Panel on Antiretroviral Guidelines for Adults and Adolescents. Guidelines for the Use of Antiretroviral Agents in HIV-1-Infected Adults and Adolescents. Washington, DC: Department of Health and Human Services. Available from: http://aidsinfo.nih.gov/ contentfiles/lvguidelines/AdultandAdolescentGL.pdf. Accessed January 13, 2014.

5. Rockstroh JK, Lennox JL, DeJesus E, et al. Long-term treatment with raltegravir or efavirenz combined with tenofovir/emtricitabine for treatment-naive human immunodeficiency virus-1-infected patients: 156-week results from STARTMRK. Clin Infect Dis. 2011;53(8): 807-816.

6. Pandey KK. Raltegravir in HIV-1 infection: safety and efficacy in treatment-naive patients. Clin Med Rev Ther. 2011;2012(4):13-30.

7. Nguyen BY, Isaacs RD, Teppler H, et al. Raltegravir: the first HIV-1 integrase strand transfer inhibitor in the HIV armamentarium. Ann $N$ Y Acad Sci. 2011;1222:83-89.

8. STRIBILD ${ }^{\circledR}$ [prescribing information]. Foster City, CA: Gilead Sciences Inc.; 2013.

9. Nachega JB, Parienti JJ, Uthman OA, et al. Lower pill burden and once-daily dosing antiretroviral treatment regimens for HIV infection: a meta-analysis of randomized controlled trials. Clin Infect Dis. Epub March 5, 2014.

10. Engelman A, Bushman FD, Craigie R. Identification of discrete functional domains of HIV-1 integrase and their organization within an active multimeric complex. EMBO J. 1993;12(8):3269-3275.

11. Krishnan L, Engelman A. Retroviral integrase proteins and HIV-1 DNA integration. J Biol Chem. 2012;287(49):40858-40866.

12. Jaskolski M, Alexandratos JN, Bujacz G, Wlodawer A. Piecing together the structure of retroviral integrase, an important target in AIDS therapy. FEBS J. 2009;276(11):2926-2946.

13. Pandey KK, Bera S, Grandgenett DP. The HIV-1 integrase monomer induces a specific interaction with LTR DNA for concerted integration. Biochemistry. 2011;50(45):9788-9796. 
14. Bera S, Pandey KK, Vora AC, Grandgenett DP. Molecular Interactions between HIV-1 integrase and the two viral DNA ends within the synaptic complex that mediates concerted integration. J Mol Biol. 2009;389(1): 183-198.

15. Hare S, Maertens GN, Cherepanov P. 3 '-processing and strand transfer catalysed by retroviral integrase in crystallo. EMBO J. 2012;31(13): 3020-3028.

16. Li M, Mizuuchi M, Burke TR Jr, Craigie R. Retroviral DNA integration: reaction pathway and critical intermediates. EMBO J. 2006;25(6): 1295-1304.

17. Pandey KK, Bera S, Vora AC, Grandgenett DP. Physical trapping of HIV-1 synaptic complex by different structural classes of integrase strand transfer inhibitors. Biochemistry. 2010;49(38):8376-8387.

18. Pandey KK, Bera S, Zahm J, et al. Inhibition of human immunodeficiency virus type 1 concerted integration by strand transfer inhibitors which recognize a transient structural intermediate. JVirol. 2007;81(22): 12189-12199.

19. Pommier Y, Johnson AA, Marchand C. Integrase inhibitors to treat HIV/AIDS. Nat Rev Drug Discov. 2005;4(3):236-248.

20. Hare S, Gupta SS, Valkov E, Engelman A, Cherepanov P. Retroviral intasome assembly and inhibition of DNA strand transfer. Nature. 2010;464(7286):232-236.

21. Hare S, Vos AM, Clayton RF, Thuring JW, Cummings MD, Cherepanov P. Molecular mechanisms of retroviral integrase inhibition and the evolution of viral resistance. Proc Natl Acad Sci U S A. 2010;107(46): 20057-20062.

22. Sato M, Motomura T, Aramaki H, et al. Novel HIV-1 integrase inhibitors derived from quinolone antibiotics. $J$ Med Chem. 2006;49(5):1506-1508.

23. Ramanathan S, Mathias AA, German P, Kearney BP. Clinical pharmacokinetic and pharmacodynamic profile of the HIV integrase inhibitor elvitegravir. Clin Pharmacokinet. 2011;50(4):229-244.

24. Min S, Song I, Borland J, et al. Pharmacokinetics and safety of S/ GSK1349572, a next-generation HIV integrase inhibitor, in healthy volunteers. Antimicrob Agents Chemother. 2010;54(1):254-258.

25. Kassahun K, McIntosh I, Cui D, et al. Metabolism and disposition in humans of raltegravir (MK-0518), an anti-AIDS drug targeting the human immunodeficiency virus 1 integrase enzyme. Drug Metab Dispos. 2007;35(9):1657-1663.

26. Kawaguchi I, Ishikawa T, Ishibashi M, Irie S, Kakee A. Safety and pharmacokinetics of single oral dose of JTK-303/GS-9137, a novel HIV integrase inhibitor, in healthy volunteers. 13th Conference on Retroviruses and Opportunistic Infections; February 5-8, 2006; Denver, CO.

27. DeJesus E, Berger D, Markowitz M, et al. Antiviral activity, pharmacokinetics, and dose response of the HIV-1 integrase inhibitor GS-9137 (JTK-303) in treatment-naive and treatment-experienced patients. J Acquir Immune Defic Syndr. 2006;43(1):1-5.

28. Mathias AA, West S, Hui J, Kearney BP. Dose-response of ritonavir on hepatic CYP3A activity and elvitegravir oral exposure. Clin Pharmacol Ther. 2009;85(1):64-70.

29. Ramanathan S, Shen G, Hinkle J, Enejosa J, Kearney BP. Pharmacokinetics of coadministered ritonavir-boosted elvitegravir and zidovudine, didanosine, stavudine, or abacavir. J Acquir Immune Defic Syndr. 2007;46(2):160-166.

30. Ramanathan S, Shen G, Cheng A, Kearney BP. Pharmacokinetics of emtricitabine, tenofovir, and GS-9137 following coadministration of emtricitabine/tenofovir disoproxil fumarate and ritonavir-boosted GS-9137. J Acquir Immune Defic Syndr. 2007;45(3):274-279.

31. Collot-Teixeira S, De Lorenzo F, Waters L, et al. Impact of different low-dose ritonavir regimens on lipids, CD36, and adipophilin expression. Clin Pharmacol Ther. 2009;85(4):375-378.

32. Foisy MM, Yakiwchuk EM, Hughes CA. Induction effects of ritonavir: implications for drug interactions. Ann Pharmacother. 2008;42(7): 1048-1059.

33. Mathias AA, German P, Murray BP, et al. Pharmacokinetics and pharmacodynamics of GS-9350: a novel pharmacokinetic enhancer without anti-HIV activity. Clin Pharmacol Ther. 2010;87(3):322-329.
34. German P, Warren D, Wei L, Zhong L, Hui J, Kearney BP. Effect of food on pharmacokinetics of elvitegravir, emtricitabine, tenofovir DF and the pharmacoenhancer GS-9350 as a fixed-dose combination tablet. 49th Interscience Conference on Antimicrobial Agents and Chemotherapy (ICAAC); September 12-15, 2009; San Francisco, CA.

35. Xu L, Liu H, Murray BP, et al. Discovery of GS-9350: A novel pharmacoenhancer without anti-HIV activity. 49th Interscience Conference on Antimicrobial Agents and Chemotherapy (ICAAC); September 12-15, 2009; San Francisco, CA.

36. Shah BM, Schafer JJ, Priano J, Squires KE. Cobicistat: a new boost for the treatment of human immunodeficiency virus infection. Pharmacotherapy. 2013;33(10):1107-1116.

37. German P, Warren D, West S, Hui J, Kearney BP. Pharmacokinetics and bioavailability of an integrase and novel pharmacoenhancer-containing single-tablet fixed-dose combination regimen for the treatment of HIV. J Acquir Immune Defic Syndr. 2010;55(3):323-329.

38. Ramanathan S, Mathias A, Wei X, et al. Pharmacokinetics of once-daily boosted elvitegravir when administered in combination with acidreducing agents. J Acquir Immune Defic Syndr. 2013;64(1):45-50.

39. Kiser JJ, Bumpass JB, Meditz AL, et al. Effect of antacids on the pharmacokinetics of raltegravir in human immunodeficiency virusseronegative volunteers. Antimicrob Agents Chemother. 2010;54(12): 4999-5003.

40. Cottrell ML, Hadzic T, Kashuba AD. Clinical pharmacokinetic, pharmacodynamic and drug-interaction profile of the integrase inhibitor dolutegravir. Clin Pharmacokinet. 2013;52(11):981-994.

41. Klibanov OM. Elvitegravir, an oral HIV integrase inhibitor, for the potential treatment of HIV infection. Curr Opin Investig Drugs. 2009;10(2):190-200.

42. Cohen C, Elion R, Ruane P, et al. Randomized, phase 2 evaluation of two single-tablet regimens elvitegravir/cobicistat/emtricitabine/ tenofovir disoproxil fumarate versus efavirenz/emtricitabine/tenofovir disoproxil fumarate for the initial treatment of HIV infection. AIDS. 2011;25(6):F7-F12.

43. Sax PE, DeJesus E, Mills A, et al. Co-formulated elvitegravir, cobicistat, emtricitabine, and tenofovir versus co-formulated efavirenz, emtricitabine, and tenofovir for initial treatment of HIV-1 infection: a randomised, double-blind, phase 3 trial, analysis of results after 48 weeks. Lancet. 2012;379(9835):2439-2448.

44. Zolopa A, Sax PE, DeJesus E, et al. A randomized double-blind comparison of coformulated elvitegravir/cobicistat/emtricitabine/tenofovir disoproxil fumarate versus efavirenz/emtricitabine/tenofovir disoproxil fumarate for initial treatment of HIV-1 infection: analysis of week 96 results. J Acquir Immune Defic Syndr. 2013;63(1):96-100.

45. Elion R, Cohen C, Ward D, et al. Evaluation of efficacy, safety, pharmacokinetics, and adherence in HIV-1-infected, antiretroviralnaive patients treated with ritonavir-boosted atazanavir plus fixeddose tenofovir DF/emtricitabine given once daily. HIV Clin Trials. 2008;9(4):213-224.

46. German P, Liu HC, Szwarcberg J, et al. Effect of cobicistat on glomerular filtration rate in subjects with normal and impaired renal function. J Acquir Immune Defic Syndr. 2012;61(1):32-40.

47. Hall AM, Hendry BM, Nitsch D, Connolly JO. Tenofovir-associated kidney toxicity in HIV-infected patients: a review of the evidence. Am J Kidney Dis. 2011;57(5):773-780.

48. Malik A, Abraham P, Malik N. Acute renal failure and Fanconi syndrome in an AIDS patient on tenofovir treatment - case report and review of literature. J Infect. 2005;51(2):E61-E65.

49. Wohl DA, Cohen C, Gallant JE, et al. A randomized, double-blind comparison of single-tablet regimen elvitegravir/cobicistat/emtricitabine/ tenofovir DF versus single-tablet regimen efavirenz/emtricitabine/ tenofovir DF for initial treatment of HIV-1 infection: analysis of week 144 results. J Acquir Immune Defic Syndr. 2014;65(3):e118-e120.

50. Lennox JL, Dejesus E, Berger DS, et al. Raltegravir versus efavirenz regimens in treatment-naive HIV-1-infected patients: 96-week efficacy, durability, subgroup, safety, and metabolic analyses. J Acquir Immune Defic Syndr. 2010;55(1):39-48. 
51. Murray JM, Emery S, Kelleher AD, et al. Antiretroviral therapy with the integrase inhibitor raltegravir alters decay kinetics of HIV, significantly reducing the second phase. AIDS. 2007;21(17):2315-2321.

52. Rockstroh JK, DeJesus E, Henry K, et al. A randomized, double-blind comparison of coformulated elvitegravir/cobicistat/emtricitabine/ tenofovir DF vs ritonavir-boosted atazanavir plus coformulated emtricitabine and tenofovir DF for initial treatment of HIV-1 infection: analysis of week 96 results. J Acquir Immune Defic Syndr. 2013;62(5): 483-486.

53. Clumeck N, Molina JM, Henry K, et al. A randomized, doubleblind comparison of single-tablet regimen elvitegravir/cobicistat/ emtricitabine/tenofovir DF vs ritonavir-boosted atazanavir plus emtricitabine/tenofovir DF for initial treatment of HIV-1 infection: analysis of week 144 results. J Acquir Immune Defic Syndr. 2014;65(3): e121-e124.

54. DeJesus E, Rockstroh JK, Henry K, et al. Co-formulated elvitegravir, cobicistat, emtricitabine, and tenofovir disoproxil fumarate versus ritonavir-boosted atazanavir plus co-formulated emtricitabine and tenofovir disoproxil fumarate for initial treatment of HIV-1 infection: a randomised, double-blind, phase 3, non-inferiority trial. Lancet. 2012;379(9835):2429-2438.

55. Arya V, Florian J, Marcus KA, Reynolds KS, Lewis LL, Sherwat AI. Does an increase in serum creatinine always reflect renal injury? The case of STRIBILD ${ }^{\circledR}$. J Clin Pharmacol. 2013;54(3):279-281.

56. Molina JM, Lamarca A, Andrade-Villanueva J, et al. Efficacy and safety of once daily elvitegravir versus twice daily raltegravir in treatment-experienced patients with HIV-1 receiving a ritonavir-boosted protease inhibitor: randomised, double-blind, phase 3, non-inferiority study. Lancet Infect Dis. 2012;12(1):27-35.

57. Elion R, Molina JM, Ramon Arribas Lopez J, et al. A randomized phase 3 study comparing once-daily elvitegravir with twice-daily raltegravir in treatment-experienced subjects with HIV-1 infection: 96-week results. J Acquir Immune Defic Syndr. 2013;63(4):494- 497.

58. Crofoot G, Ortiz R, Mills A, et al. Safety and tolerability of switching from twice daily raltegravir plus truvada to STRIBILD in virologically suppressed, HIV-1-infected subjects at week 24. 7th IAs Conference on HIV Pathogenesis, Treatment and Prevention; Jun 30-July 3, 2013; Kuala Lumpur, Malaysia.

59. Shimura K, Kodama E, Sakagami Y, et al. Broad antiretroviral activity and resistance profile of the novel human immunodeficiency virus integrase inhibitor elvitegravir (JTK-303/GS-9137). J Virol. 2008;82(2):764-774.
60. Goethals O, Clayton R, Van Ginderen M, et al. Resistance mutations in human immunodeficiency virus type 1 integrase selected with elvitegravir confer reduced susceptibility to a wide range of integrase inhibitors. J Virol. 2008;82(21):10366-10374.

61. Margot NA, Hluhanich RM, Jones GS, et al. In vitro resistance selections using elvitegravir, raltegravir, and two metabolites of elvitegravir M1 and M4. Antiviral Res. 2012;93(2):288-296.

62. Mesplede T, Quashie PK, Osman N, et al. Viral fitness cost prevents HIV-1 from evading dolutegravir drug pressure. Retrovirology. 2013;10:22

63. Quashie PK, Mesplede T, Han YS, et al. Characterization of the R263K mutation in HIV-1 integrase that confers low-level resistance to the second-generation integrase strand transfer inhibitor dolutegravir. J Virol. 2012;86(5):2696-2705.

64. Blanco JL, Varghese V, Rhee SY, Gatell JM, Shafer RW. HIV-1 integrase inhibitor resistance and its clinical implications. J Infect Dis. 2011;203(9):1204-1214.

65. Zahm JA, Bera S, Pandey KK, et al. Mechanisms of human immunodeficiency virus type 1 concerted integration related to strand transfer inhibition and drug resistance. Antimicrob Agents Chemother. 2008;52(9):3358-3368.

66. Marinello J, Marchand C, Mott BT, Bain A, Thomas CJ, Pommier Y. Comparison of raltegravir and elvitegravir on HIV-1 integrase catalytic reactions and on a series of drug-resistant integrase mutants. Biochemistry. 2008;47(36):9345-9354.

67. Metifiot M, Maddali K, Naumova A, Zhang X, Marchand C, Pommier Y. Biochemical and pharmacological analyses of HIV-1 integrase flexible loop mutants resistant to raltegravir. Biochemistry. 2010;49(17):3715-3722.

68. Abram ME, Hluhanich RM, Goodman DD, et al. Impact of primary elvitegravir resistance-associated mutations in HIV-1 integrase on drug susceptibility and viral replication fitness. Antimicrob Agents Chemother. 2013;57(6):2654-2663.

69. Christ F, Voet A, Marchand A, et al. Rational design of small-molecule inhibitors of the LEDGF/p75-integrase interaction and HIV replication. Nat Chem Biol. 2010;6(6):442-448.

70. Engelman A, Kess1 JJ, Kvaratskhelia M. Allosteric inhibition of HIV-1 integrase activity. Curr Opin Chem Biol. 2013;17(3):339-345.
HIV/AIDS - Research and Palliative Care

\section{Publish your work in this journal}

HIV/AIDS - Research and Palliative Care is an international, peerreviewed open-access journal focusing on advances in research in HIV, its clinical progression and management options including antiviral treatment, palliative care and public healthcare policies to control viral spread. The journal welcomes original research, basic science,

\section{Dovepress}

clinical \& epidemiological studies, reviews \& evaluations, expert opinion \& commentary, case reports \& extended reports. The manuscript management system is completely online and includes a very quick and fair peer-review system. Visit http://www.dovepress.com/ testimonials.php to read real quotes from published authors. 